\title{
Total nitrogen determination by a spectrophotometric method
}

\section{Koistinen, Jaana}

Humana press

2020

Koistinen , J , Sjöblom , M A \& Spilling , K 2020 , Total nitrogen determination by a spectrophotometric method . in K Spilling (ed.), Biofuels from Algae : Methods and

Protocols . vol. 1980 , Methods in Molecular Biology , Humana press , New York , pp. 81-86

.https://doi.org/10.1007/7651_2019_206

http://hdl.handle.net/10138/317337

https://doi.org/10.1007/7651_2019_206

cc_by

acceptedVersion

Downloaded from Helda, University of Helsinki institutional repository.

This is an electronic reprint of the original article.

This reprint may differ from the original in pagination and typographic detail.

Please cite the original version. 
Methods in Molecular biology (2020) 1980: 81-86

DOI 10.1007/7651_2019_206

\section{Total nitrogen determination by a spectrophotometric method}

Jaana Koistinen $^{1}$, Mervi Sjöblom ${ }^{1}$, Kristian Spilling ${ }^{2}$

${ }^{1}$ Tvärminne Zoological Station, University of Helsinki, JA Palménin tie 260, 10900 Hanko, Finland

${ }^{2}$ Finnish Environment Institute, PO Box 140, 00251 Helsinki, Finland

Corresponding author:

Jaana Koistinen

Email: jaana.koistinen@helsinki.fi 


\begin{abstract}
Being able to measure total nitrogen $(\mathrm{TN})$ is important for following the nitrogen budget. In this chapter, we present the spectrophotometric method we use for determining TN. The method relies on oxidation and reduction steps, involving persulfate digestion of nitrogen compounds into nitrate followed by spectrophotometric determination.
\end{abstract}

Key words: nutrient uptake, total nitrogen

Running title: Determining total nitrogen 


\section{Introduction}

Total nitrogen (TN) includes all forms of nitrogen (organic and inorganic) that is found in the water, with the exception of the gas phase $\left(\mathrm{N}_{2}\right)$, and is defined as the nitrogen that gives rise to nitrite/nitrate ions. In practice, $\mathrm{TN}$ is the sum of nitrite, nitrate, ammonia, and dissolved and particulate organic nitrogen. $\mathrm{TN}$ is an important variable to measure for keeping track of the nitrogen budget, and is commonly used for monitoring the state of the environment in lakes and the ocean, and also for monitoring waste streams and cultivations in aquatic environments.

In this chapter we present the method we use for determining total nitrogen. The method is based on colorimetric principles, measuring nitrogen after a persulfate oxidation of nitrogen compounds in alkaline conditions to nitrate, reduction step, and addition of chemicals reacting with the $\mathrm{N}$-containing molecule [1]. Nitrate formed during the oxidation is reduced to nitrite here with an acidic vanadium chloride reagent [2], which is simultaneously added with amines forming a colored compound, an azo dye, that is detectable spectrophotometrically. Total dissolved nitrogen (TDN) can be determined after filtering the sample, which excludes the particulate organic carbon (PON). TDN can be measured together with dissolved organic carbon (DOC) using high temperature $\left(>700^{\circ} \mathrm{C}\right)$ catalytic oxidation [1]. PON can be determined using combustion at higher temperature $\left(\sim 1000^{\circ} \mathrm{C}\right)$ with an oxidation catalyst followed by reduction to $\mathrm{N}_{2}$ (or determined as the difference between TN in unfiltered and filtered samples) [1]. Dissolved organic nitrogen (DON) can be determined as the difference between TDN and dissolved inorganic nitrogen (DIN; the sum of all dissolved inorganic nitrogen species). 


\section{Materials}

Use only analytical grade reagents.

\subsection{Total nitrogen}

1. Boric acid $\left(\mathrm{H}_{3} \mathrm{BO}_{3}\right)$.

2. Concentrated hydrochloric acid $(37 \% \mathrm{HCl})$.

3. Disodium ethylenediaminetetraacetate dihydrate (Na2-EDTA;

$\mathrm{C}_{10} \mathrm{H}_{14} \mathrm{~N}_{2} \mathrm{Na}_{2} \mathrm{O}_{8} \cdot 2 \mathrm{H}_{2} \mathrm{O}$; e.g., Titriplex® III).

4. $\mathrm{N}$-(1-naphtyl)-ethylenediamine dihydrochloride $\left(\mathrm{C}_{10} \mathrm{H}_{7} \mathrm{NHCH}_{2} \cdot \mathrm{CH}_{2} \cdot \mathrm{NH}_{2} \cdot 2 \mathrm{HCl}\right)$.

5. Potassium peroxodisulfate $\left(\mathrm{K}_{2} \mathrm{~S}_{2} \mathrm{O}_{8}\right)$ with low nitrogen content (e.g., Merck 1.05092).

6. Sodium hydroxide $(\mathrm{NaOH})$.

7. Sulphanilamide $\left(\mathrm{NH}_{2} \cdot \mathrm{C}_{6} \mathrm{H}_{6} \cdot \mathrm{SO}_{2} \cdot \mathrm{NH}_{2}\right)$.

8. Vanadium chloride $\left(\mathrm{VCl}_{3}\right)$.

9. Ultrapure water (e.g., Milli-Q).

10. $25 \mathrm{ml}$ reaction flasks with screw caps (e.g., Pyrex containers).

11. $10 \mathrm{ml}$ reaction tubes with screw caps (e.g., Pyrex containers).

12. $50 \mathrm{ml}$ graduated cylinders.

13. 50-1000 ml volumetric flasks.

14. $100-1000 \mathrm{ml}$ storage bottles.

15. Spatulas.

16. Adjustable pipettes and pipette tips.

17. $1 \mathrm{~cm}$ plastic cuvettes or flow-through cuvette.

18. Analytical balance.

19. Autoclave.

20. Oven capable of being maintained at $45^{\circ} \mathrm{C}$. 
21. Refrigerator.

22. Spectrophotometer or automatic analyzer.

\section{Method}

Use acid-washed glassware (soaked for $4 \mathrm{~h}$ in $6 \% \mathrm{HCl}$ and rinsed with deionized water).

\subsection{Total nitrogen}

The procedure follows that of Koroleff in the first edition of [1] and [3] (excluding the reduction and reaction to the azo dye that is performed here with a combined reagent, containing $\mathrm{VCl}_{3}$ reduction solution as in [2]).

1. Prepare $0.075 \mathrm{~mol} / \mathrm{l}$ sodium hydroxide solution by dissolving $3 \mathrm{~g}$ sodium hydroxide in $1000 \mathrm{ml}$ of ultrapure water (Note 1).

2. Prepare oxidizing reagent by dissolving $10 \mathrm{~g}$ potassium peroxodisulfate and $6 \mathrm{~g}$ boric acid in $110.075 \mathrm{~mol} / \mathrm{l}$ sodium hydroxide solution (Notes 2 and 3). Store in a brown glass bottle in a refrigerator (stable for several weeks).

3. Prepare sulphanilamide solution (nitrite reagent $\mathrm{I}$ ) by dissolving $1.0 \mathrm{~g}$ sulphanilamide in a mixture of $85 \mathrm{ml}$ ultrapure water and $14.5 \mathrm{ml}$ concentrated $\mathrm{HCl}$. Store in a glass bottle at room temperature.

4. Prepare N-(1-naphtyl)-ethylenediamine dihydrochloride (NED) solution (nitrite reagent II) by dissolving $0.07 \mathrm{~g}$ NED in $100 \mathrm{ml}$ ultrapure water. Store in a brown glass bottle in a refrigerator (renew if the color is brown; stable about 1 month).

5. Prepare vanadium chloride solution by dissolving $1.6 \mathrm{~g}$ vanadium chloride in a mixture of $170 \mathrm{ml}$ ultrapure water and $16.8 \mathrm{ml}$ concentrated $\mathrm{HCl}$, and then add 
ultrapure water to a final total volume of $200 \mathrm{ml}$. Store in glass bottle in a refrigerator (stable about 1 month).

6. Prepare TN mix-reagent by mixing $100 \mathrm{ml}$ vanadium chloride solution with $20 \mathrm{ml}$ sulphanilamide solution and $20 \mathrm{ml}$ amine solution. Store in a refrigerator or freeze (prolongs stability).

7. Prepare total nitrogen standard $140 \mu \mathrm{g} / \mathrm{ml} \mathrm{N}(10 \mu \mathrm{mol} / \mathrm{ml} \mathrm{N})$ by dissolving $0.1862 \mathrm{~g}$ $\mathrm{Na}_{2}$-EDTA in ultrapure water, and then add ultrapure water to a final total volume of $100 \mathrm{ml}$. Store in a glass bottle in a refrigerator (stable for several months).

8. On the day of analyses, prepare working solutions of total nitrogen $(0-600 \mu \mathrm{g} / \mathrm{l})$ for calibration by diluting the standard stock solution (see Step 7) with ultrapure water (e.g., $1 \mathrm{ml}$ to $50 \mathrm{ml}$ for $2800 \mu \mathrm{g} / \mathrm{l}$ solution and then, e.g., $10 \mathrm{ml}$ of this dilution to 50 ml ultrapure water for $560 \mu \mathrm{g} / \mathrm{l}$ solution).

9. Pipette $5 \mathrm{ml}$ of each calibration standard and $5 \mathrm{ml}$ of ultrapure water for blanks to reaction flasks (see Note 4).

10. Add $5 \mathrm{ml}$ oxidizing reagent solution to each flask and close the flask. Mix by swirling, autoclave for $30 \mathrm{~min}$, and allow to cool to room temperature.

11. Prepare spectrophotometer or analyzer for analyses according to the operation manual (see Note 5).

12. Perform manual analyses with a spectrophotometer or place standards in the autosampler of an analyzer for a calibration curve and linearity test (see Note 6).

13. For manual analyses, pipette $0.5 \mathrm{ml}$ of the oxidized standards and blanks to reaction tubes. Add $3 \mathrm{ml} \mathrm{TN}$ mix-reagent to each tube and close the tubes. Mix well by swirling, incubate for $1 \mathrm{~h}$ at $45^{\circ} \mathrm{C}$, and allow to cool to room temperature.

14. Measure the absorbance of blanks and standards with a spectrophotometer in a $1 \mathrm{~cm}$ cuvette (or flow-through cuvette) at $545 \mathrm{~nm}$ for a calibration curve (see Note 6). 
15. Collect the samples in glass bottles or polyethylene bottles, and analyze the samples immediately after collection. The sample can be stored in a glass bottle in a refrigerator for a day.

16. Pipette $5 \mathrm{ml}$ of sample (or diluted sample; see Note 7) to reaction flasks.

17. Add $5 \mathrm{ml}$ oxidizing reagent to each flask and close the flasks. Add $5 \mathrm{ml}$ oxidizing reagent to three empty flasks for reagent blanks (see Note 8). Mix by swirling, autoclave for $30 \mathrm{~min}$, and allow to cool to room temperature.

18. Add $5 \mathrm{ml}$ ultrapure water to the reagent blanks, close the flasks, and mix well.

19. Perform manual analyses with a spectrophotometer, or place the samples and reagent blanks in the autosampler of an analyzer. Verify proper operation of the instrument with certified reference material, and include ultrapure water blanks in the run (see Note 9).

20. For manual analyses, pipette $0.5 \mathrm{ml}$ of the oxidized samples and reagent blanks to reaction tubes. Add $3 \mathrm{ml}$ TN-mix reagent to each tube and close the tubes. Mix well by swirling, incubate $1 \mathrm{~h}$ at $45^{\circ} \mathrm{C}$, and allow to cool to room temperature.

21. Measure the absorbance of the reagent blanks and samples with a spectrophotometer in a $1 \mathrm{~cm}$ cuvette (or flow-through cuvette) at $545 \mathrm{~nm}$, and calculate the total nitrogen concentration by the calibration curve (see Note 10).

\section{Notes}

1. The strength of the $\mathrm{NaOH}$ solution should ensure that excess $\mathrm{OH}^{-}$ions are present after the composition of the oxidant. The amount of $\mathrm{NaOH}$ in the solution should be adequate for neutralization of the $2 \mathrm{~mol}$ of $\mathrm{H}^{+}$formed per mol of persulfate. 
2. For complete oxidization of organic material, oxygen available from the persulfate oxidation should be at ten times greater level than that of organic material in the sample.

3. Total nitrogen and total phosphorus can be analyzed after simultaneous oxidation with persulfate using more concentrated oxidizing reagent.

4. Use five different dilution steps for calibration, and determine the blank with ultrapure water since ultrapure water may contain nitrogen traces.

5. It is critical to have proper training before running the analyzer. This will depend on the system that you are using, and it is beyond the scope of this chapter to go into the details of the operation of the instrument. We have used a Hitachi $1100 \mathrm{UV}$ spectrophotometer for TN analysis.

6. Calibration curve is prepared by plotting measured absorbance or area of standards versus standard concentrations (linear regression). Reduce the absorbance of the blank from the absorbance of the standards.

7. If the total nitrogen content is higher than $600 \mu \mathrm{g} / \mathrm{l}$, the sample should first be diluted with ultrapure water. The total carbon content of the sample should not exceed 20 $\mathrm{mg} / \mathrm{l}$ when using $5 \mathrm{ml}$ of the oxidizing solution for $5 \mathrm{ml}$ of sample.

8. Determine the blank caused by the oxidant since persulfate contains traces of nitrogen.

9. Start each sample run with ultrapure water blank(s) and reference material to verify proper operation of the instrument. Analyze samples in sequences of max 20 samples followed by a blank and reference material. Insert also standards in the sequence to test accuracy and drift during the analytical runs.

10. Determine concentration in the sample by the slope of the calibration curve. Reduce the absorbance of the measured reagent blank and the reagent blank value taken from 
the intercept of the calibration line with the ordinate from the absorbance of the sample.

\section{References}

[1] Grasshoff K, Ehrhardt M, Kremling K (1999) Methods of seawater analysis. Wiley-VCH Verlag Gmbh, Weinheim.

[2] Schnetger B, Lehners C (2014) Determination of nitrate plus nitrite in small volume marine water samples using vanadium(III)chloride as a reduction agent. Mar.Chem. 160:9198.

[3] Koroleff F (1979) Methods for the chemical analysis for seawater. Meri 7: 1-60 (in Finnish). 